\title{
Freedoms in the Classroom: Cultivating a Successful Third Space for Literacy Growth
}

\author{
SUE NASH-DITZEL \\ Ledyard Center School \\ TAMMY BROWN \\ Marywood University
}

\begin{abstract}
This phenomenologically-based, teacher research study looked at themes across the interviews of college students after they participated in the Digital Reading Log (DRL), a literacy-based activity utilizing the Internet, word processing software, and email. The purpose of this study was to investigate students' experiences in the basic skills reading classroom while engaged with the DRL. Findings indicate that the DRL afforded the students various freedoms, such as freedom of language and choice. The data suggested that the instructor was able to draw upon these freedoms to effectively create a Third Space that improved struggling young adult readers' understanding of text while increasing their motivation to read.
\end{abstract}

\section{A Vignette: Inside a College Basic Skills Reading Classroom}

As I explain the activity I created called The Digital Reading Log to my basic skills reading class, comprised of 18-and 19-year-old college freshmen, I can see the suspicion in their eyes; they are wary of my instructions. "Ok, so let me recap because you're giving me that, 'I think the professor has lost her marbles look.' Search the Internet for an article you find interesting, cut and paste it into a document and use the 'insert comment' function in the Microsoft Word program to record the thoughts you have as you read the article. Then swap articles, via email, with your partner, read his or her commented-on article and comment back."

Silence ... a few sighs, some yawns, and the rhythmic symphony of multiple cell phones, set on vibrate, jiggling around in oversized purses. They stare fiercely at their computers, which seems odd since I haven't asked them to turn them on yet. Innately, I know they have all covertly logged onto Facebook when they thought I wasn't looking. This response is normal; I am not surprised or angered. Students in basic skills or developmental classes at community college tend to have had few positive experiences in the classroom and very little about school excites them. "All right, let's just give it a try," I blurt out, not knowing how else to simplify the directions.

The students dutifully begin to scour websites such as Yahoo.com and AOL.com for interesting articles. Many of them choose pop culture pieces on music, movies, and celebrities. They finish this part quickly and with ease. They've been on these websites innumerable times; they cut and paste their articles into a Word document and begin to read.

Paige looks up from her screen and yells out, "You mean we just write anything?"

I respond, "Yes. So as you're reading, record any thoughts that pop into your mind." 
She does not seem completely satisfied as she squints at me, confused and annoyed by my response. Thirty second later she yells out again, "Are you sure we can write anything ... like, even if it's not proper?"

I don't exactly know what Paige means by "not proper," so to avoid complication I repeat, "Write whatever comes to your mind while you are reading." I watch Paige as she cautiously begins to type something into a comment box. She types slowly, then a little faster, until her wildly colored acrylic fingernails are moving across the keyboard like miniature flamenco dancers. "This is great!" she shouts out, not taking her eyes off the screen or her fingers off the keyboard.

A few students sitting close by giggle at her enthusiasm, but concur that they are enjoying this activity. I watch as 16 sets of eyes absorbedly read. I am fascinated by the sheer intensity of their reading, as well as how much they type. I can hardly get them to pick up a pen in class, never mind write something. And read an entire article - forget it! We are running short on time and I announce that their homework will be to finish their reading logs. Many ask if they can stay in the computer lab and finish. I am taken aback by this response. Why are they suddenly engaged in this literacy task?

Engaging college freshmen who have struggled with reading their entire lives is not an easy feat. In fact, after four years of teaching basic skills reading, I have never heard students ask to stay after class to read and write. For this reason, I decided to further explore students' experiences with the DRL activity. The purpose of this study was to investigate the question: From the perspective of the students, why did the DRL motivate and engage young adult readers who historically struggled with literacy and, therefore, were reluctant to read and write? Following is a brief review of the literature on Third Space Theory, reading engagement, and the role technology plays in reading motivation, which, collectively, was the framework used to explore this phenomenon.

\section{A Review of the Literature}

\section{Third Space Theory}

Current research speaks to the value of incorporating students' everyday conceptual knowledge or out-of-school knowledge (first space), into scientific concepts or in-school knowledge (second space) (Delpit, 2006; Moje, Ciechanowski, Kramer, Ellis, Carrillo, \& Collazo, 2004; Vygotsky, 1978;) as a way to create a Third Space in which learning is enhanced (Guiterrez, 2008). Moje et al. (2004) conceptualized three distinct views of Third Space in the current literature as it pertains to educational contexts. The first view sees Third Space as a mechanism bridging in- and out-of-school knowledge and Discourse ${ }^{i}$. In this view, Third Spaces are places where marginalized voices are valued and success in the traditional school setting is promoted. A second view posits that Third Space acts as a "navigational space" that allows students to successfully move in and out of various discourse communities. That is, understanding the discourse of a particular subject will ultimately lead to a greater understanding of that subject, as well as support learning across other disciplines. The last view situates Third Space as a way in which differing beliefs and practices that are connected to cultural or social groups can be addressed so as to "reshape" literacy practices in and outside of the classroom.

Building on the seminal work by Moll, Armanti, Neff, and Gonzalez (1992) on "funds of knowledge," the Third Space can be guided and shaped to create a "transformative space where 
the potential for an expanded form of learning and the development of new knowledge are heightened" (Gutierrez, 2008, p. 152). Similar to Vygotsky's (1978) Zone of Proximal Development (ZPD), successfully created Third Spaces scaffold learning by recognizing the reciprocal relationship between teachers, students, activities, and in- and out-of-school funds of knowledge, including language, culture, and beliefs. In the Third Space, these relationships can be organized to bolster and sustain learning. While the premise of Third Space seems reasonable, creating these spaces within the classroom can be challenging.

Moje et al. (2004) found that middle school students often possessed a vast array of outof-school funds of knowledge that could possibly be brought into class discussions on certain topics to deepen learning. However, a merger of in- and out-of-school funds was rarely seen in their study. Students did not willingly suggest out-of-school connections, which were mentioned to the researchers during interviews, and teachers did not actively draw on students' funds of knowledge. One suggestion to explain this lack of merger was that students perceived a definite separation between in- and out-of-school knowledge and, thus, did not consider blending the two.

Additionally, Third Spaces are places where contested thoughts, values, beliefs and languages are exposed (Gutierrez, 2009). Consequently, these spaces may not always be comfortable. Gutierrez, Rymes, and Larson (1995) found that even when a prime opportunity arose in the classroom to integrate students' out-of-school funds into the instructional goals, this did not occur. In one example, the class was discussing Brown v. Board of Education, a seminal Supreme Court case regarding reversing the policy to racially segregate black and white students in the Topeka, Kansas public school system. During the lesson, a myriad of Third Space opportunities materialized, such as issues of race and miscegenation, yet none were expanded upon. The authors explained that there was a "retreat from the third space" on the part of the teacher due to it being "uncomfortable territory" (Gutierrez et al., 1995, p. 466).

Researchers have found that students whose language practices do not resemble those practiced in classrooms will struggle to acquire new concepts (Gee, Michaels, \& O'Connor, 1992). However, this need not be the case. Gee (1996) asserts that discourses are based in culture and ideologies which are formed through the practices of a particular group. The classroom has the potential to be a hybrid space in which students' out-of-school language practices can be brought into school and used as a tool to facilitate and extend literacy growth.

The use of popular culture in the classroom can be a means of bridging the gap between students' out-of-school and in-school literacies. Moje, Overby, Tysvaer, and Morris (2008) argue that students are engaging in a great deal of reading and writing acts outside of school, but they are not reading and writing the kinds of texts that are valued by teachers. Moje et al. (2008) extend Gee's (1996) notion of discourse, stating, "Popular culture is a unique kind of network because it is not held together by a gathering of people but rather by information, ideas, and practices generated in and from popular texts" (p. 137). Heron-Hruby, Hagood, and Alvermann (2008) note that while educators may not acknowledge the "unsanctioned texts" brought into the classroom by students, their presence exists and serves to "...teach us, as adults, about the ways in which their uses of popular culture texts work to reference, discredit, or complement other standardizing practices, such as school literacies" (p. 314). Alvermann and Hagood (2000) conclude:

...the present discourse of schooling in this country is ill-equipped to support the 
incorporation of critical media literacy in such curricula. The binaries of in-school and out-of-school literacies will need to be blurred if we are to move beyond the current discourse... To ignore the importance of doing so in these New Times is to shortchange adolescents destined to live out their lives, literate or otherwise, in a highly technical and global 21st century. (p. 203)

Thus, there is seemingly a great urgency for teachers, especially those who are not familiar with the out-of-school literacy practices of their students, to find creative ways to harness students" "street smarts" (Delpit, 2006).

\section{Engaged Reading and Comprehension}

A reader who is engaged is motivated, strategic, knowledge-driven, and socially interactive during literacy activities (Guthrie et al., 2007). Accordingly, the more engaged a student is in a text, the higher his/her achievement (Guthrie \& Wigfield, 2000). However, when students become disengaged with school literacy practices, they inevitably struggle (Guthrie \& Davis, 2003). Additionally, research has shown that as students progressed through grade levels, literacy engagement dropped significantly (Eccles \& Midgley, 1989). Further, Guthrie and Davis (2003) wrote that a "students' reading motivation must be redeveloped to make possible the long process of acquiring cognitive skills for reading comprehension" (p. 70). In other words, simply supplying students with reading strategies or skills will have little impact unless they are motivated to read.

Researchers have concluded that there are several ways to develop students' engagement with literacy. First, there must be accessibility to a wide range of materials that students are able and motivated to read (Moore, Bean, Birdyshaw, \& Rycik, 1999). Second, allowing students to choose the texts they read and the tasks they carry out with those texts (Reynolds \& Symons, 2001) plays a significant role in reading engagement. Third, interest in the texts (Schiefele, 1999), as well as opportunities to discuss texts in a social context, particularly with peers, has been shown to be imperative in developing engaged readers (Gambrell, 1996).

\section{The Connection between Technology and Literacy Engagement}

Research that looks at the link between technology and reading engagement is limited (Pearson et al., 2005). However, the available research has shown that by incorporating technology into literacy tasks, engagement and motivation increased (LeLoup \& Ponterio, 2003; Meskill \& Mossop, 2000; Warschauer, 2006). Warschauer, (2006) found that incorporating technology into the classroom increased literacy engagement amongst struggling readers. The interactive and collaborative nature of digital texts is a possible explanation as to why students' engagement and comprehension rise when reading such materials (Labbo, 2006; Warschauer, 2006). Furthering the idea that it is the interactivity of digital texts that appeals to students, research supports that sharing information and communicating with peers, which is possible through digital texts, is a significant element in engaging students (Leu, Kinzer, Coiro, \& Cammack, 2004). Warschauer (2006) proposes that by affording students the opportunity to "actively participate in text-mediated intermental dialogue around issues of importance to their lives and communities," (p. 8) positive literacy outcomes will, indeed, follow. A natural connection appears to exist between the above ideas regarding the collaborative nature of digital texts and the notion of Third Space as reported by Gutierrez et al. (1997), who explain that when

Language \& Literacy

Volume 14, Issue 3, 2012
Page 98 
students are able to collaboratively engage in tasks, "their knowledge and literacies became available to one another" (p. 370), creating a ZPD, or Third Space.

\section{Methods}

\section{The Digital Reading Log Activity (DRL)}

The DRL is an activity, designed by the first author, where students search the Internet for articles that appeal to their individual interests. Once an article is located, students can copy, cut, and paste the article, along with all reference information, pictures, graphs and links into a Microsoft Word document. Students are directed to read the texts and use the "new comment" function in the Microsoft Word program to record ideas, questions, and opinions that enter their minds while reading. This is done by highlighting a section of text, clicking the "review" tab and then clicking "new comment." A dialogue box emerges in the right hand column and students are free to type as much as they desire, as the box expands accordingly. No specific writing prompts are given, so as to make this activity student-driven rather than teacher-led.

After reading and commenting on the article, students will save their "commented-on" article and send, via email, to another classmate. The classmate receiving the email reads the commented-on article and makes new comments and/or comments on the first reader's comments. The article is then emailed back to the first reader who reads the newly added comments and saves the article in the folder, prints, or emails the article to the instructor.

Once the DRL is completed by a pair of students, the instructor can review the log to follow the metacognitive thought processes that occurred while the students were reading the text. "User names" for each student's comments can also be individualized. Depending on the comments, the instructor can gauge the level of understanding of the students. The pair should be encouraged to share their articles and comments with other students through email or verbal discussion in small groups in class to allow for more social interaction and increased knowledge acquisition.

\section{Background of the Study}

This phenomenological, teacher research project was conducted by the two authors and involved first-year community college freshmen. The focal college enrolled roughly 14,000 students and was located in the Mid-Atlantic region of the United States. The students involved in the study were required to take a two-semester, basic skills reading course. They were in their second semester and were in the first author's class. The class was involved in the DRL process for five weeks. At the end of the five-week period, the students were asked to volunteer to be interviewed regarding their experiences with the DRL activity.

Five students expressed interest in being involved in the project. All were presented with and signed consent forms that stated the objectives of the study and what the interview would entail. The form explained that students' participation in the study would not impact their grades and that they could withdraw from the study at any time. The participants were emailed their typed transcripts to make any changes, but none were suggested.

The five participants were part of a larger class of 16 students. While participation in the study was offered to the entire class via a verbal announcement, only five of the 16 volunteered. These five students attended class regularly, yet varied in their level of participation in class as well as the quality of their work. The participants represented "typical" students enrolled in the 
reading course. The Accuplacer assessment scores (a placement test created by The College Board), which determines enrollment in the reading course, indicated that the participants were approximately at the same "level." It should be noted that the Accuplacer test does not measure reading levels. The test is comprised of twenty comprehension questions based on a reading passage. The questions measure students' understanding of main idea, implicit and explicit statements, as well as sentence relationships. As the Accuplacer is a computer-based test, the twenty questions are adaptive in that a correct answer on the first question will lead to a progressively harder second question, and so on. Conversely, question difficulty will decrease when questions are answered incorrectly. A collective score is generated and used to place students into regular or basic skills courses. Each college designates its own acceptable cutoff scores. The students in this study, as well as the rest of the students in the basic skills reading class, received a score below 50 on the test. A second, more accelerated basic skills reading class is offered at the focal college for students who score between 51 and 80. Students scoring above 80 are not required to enroll in a basic skills reading course.

The instructions for the DRL included choosing an article that was of interest to the reader that would take approximately 30 minutes to read and comment on. Additionally, students were required to read, comment, and send one article a week, as well as read and comment on an article sent from their partners. Pairs were also required to present their articles and comments to other peers during class time in roundtable-like contexts on a weekly basis. Students tended to choose articles that could be categorized into two distinct groups. One group of articles focused on popular culture, such as celebrities, movies, music, fashion, relationships and so on. The second group of articles was based on crime or police-type stories found in the news. Articles typically came from the students' homepages such as Yahoo.com or AOL.com. One participant, who was particularly interested in working with children with special needs, often searched the internet specifically for those types of articles. Another participant searched for humorous articles via his email homepage. As a whole, the articles were not tremendously complex, yet some of the vocabulary was advanced. Additionally, the phrasing or use of playful similes and metaphors required the students to infer points being made.

\section{The Participants}

All five participants in the study were 18-to-19-years of age. They were asked to briefly describe themselves as readers and as students in the past and present. They are introduced in the following section in their own voices. To ensure smoother reading of their descriptions, the researchers' question prompts and responses have been removed. Linking phrases, created by the authors, are italicized. All of the names in the study are pseudonyms. It should be noted that a member check was done on the participants' descriptions of themselves. They were emailed their "final" descriptions, complete with linking phrases and given the opportunity to make changes; none were made.

Paige, a 19-year-old African American woman describes herself as a high school student, as well as a college freshman: In high school I was smart, but bad. I was suspended a lot. I failed a lot of classes. I would describe myself, in high school, as immature. I always liked drama. Never really cared too much about school. I really didn't like to read cuz I could read something and not know what it was about, like, I would forget it real easy." In college, "I'm mature now. I don't like drama now. I don't like to be involved in anything, I just worry about school." I've changed "because I realize you can't do anything unless you have a degree. Well, you can do 
better if you have a degree. I want to be DYFS (Department of Youth and Family Services) case worker" so I'm transferring "to Georgia State in the fall." As a student "I get good grades now, and I'm more focused." As a reader I've changed, "A whole lot. I never knew anything about annotating or any way to help you remember. Now that I annotate, it's easier for me. I understand the passage."

Kevin, an 18-year old African American college freshman reflects on himself as a student and reader beginning in elementary school and continuing to the present: In "elementary school I was in 'resource reading'... because I could barely read in elementary school. I had an IEP." I guess you could say I just wasn't that happy in high school. It had nothing to do with the people, I just didn't like school itself, so I kind of just sat in the back. For the first couple of years" in high school "I did horrible. I almost got held back in $10^{\text {th }}$ grade. I just didn't do my homework. I just always found that I wanna keep my school work in school, not at home. That's how I always felt, but as I realized that I was failing I was like, 'OK, I guess I have to do it now.' So in 11 th and 12th grade I did ok. Passed with Bs and Cs - no A's because-I don't know why." As a reader "I don't like reading books. The only way I'll like read a book is if I'm forced to for school. Other than that I won't read. Like, I'll read a magazine if I really, really want to read it. Or a newspaper article, if I'm really interested in what's it about, but other than that I won't read it." Now as a college student, "I'm not quiet anymore, I've grown up a lot. I get A's now. I like college a lot more than high school. I guess that's the difference." As a reader, "I'll like go to the dictionary or use that fix-up stuff to figure out a word sometimes."

Aisha, an 18-year-old African American woman describes her journey through school in the following way: As a student in high school I received "A/B honor role all four years. I always had my work on time." As a reader, "I was alright. I took awhile to actually understand what I was reading, but otherwise I'm OK." If I had to describe how I've changed now that I'm in college I could say I'm "more mature. I'm more outgoing. I'm not as shy. I grew out of my being shy and catching a heart attack in front of everybody. Everything is the same" about myself as a student, but as a reader, "I'm better. Before I used to rush and stuff but now if I take my time I'll understand it quicker so it's somewhat the same, somewhat different." Now, in college, "your grades matter. It gets you into your career so it makes sense to actually do your work and understand it. I'm probably going to transfer somewhere in the city" because "I do want to be a personal stylist for someone."

Whitney, an 18-year-old Caucasian woman took an intricate look back over her years in school up to college: "I was in special education classes. That was from middle school until my sophomore or junior year in high school, but I never really asked for help that much. It was a little difficult, but it was easier because the classes were so small so you got the attention you needed from the teacher. I gradually went into the bigger classes and I was on my own so it was a tiny bit difficult." Throughout school "I was a very hardworking person that tried to get along with everyone and stayed away from all the drama in school. I didn't really like to do some of the work, but I was loved by all the teachers because I was a really nice kid." As a reader in high school I could "read things in my mind, I could read things so easy, but when I read it out loud I can't read it. I don't know why. It's like big words, it's really difficult. My teacher would randomly call on people so I didn't read as much as I should have." Now in college I have "definitely" changed as a reader. I'm "trying to understand what the author is trying to say. Annotating has made it easier for me to read it and understand what the person is saying and if I took a test on it I would know exactly what you were talking about, so it's a lot easier with these 
other classes."

Vicky, an 18-year-old-year Hispanic American explained her academic journey as a student and reader beginning in high school: In high school, "I was lazy. I didn't really care, cuz I like, procrastinate. Freshmen and sophomore year I did really good and then like junior and senior year I was like, 'I don't care anymore." But here at college "I do a lot better now. I get A's in all my classes. And I'm surprised about that. I try. Like if I don't get an A I don't like it. I think" I've changed "cuz my parents pay for it and I don't want to let my parents down. My dad didn't go to college, so I don't want to waste their money." As a reader, "I think I'm getting better. Now I ask questions, like just when I'm annotating, so I just like write it down." I'm "understanding from the annotating and the background knowledge. All the strategies. It helped a lot. I tell my boyfriend to do it too, when he doesn't understand something. I'll write little notes for him" in his textbooks. "It's like plugged into my brain now."

\section{Data Collection and Analysis}

\section{Subjectivity Statement}

Upon setting out to explore the students' experiences with the DRL, it was our "commonsense thesis" (Polkinghorne, 1989, p. 46) that the students' heightened interest and engagement in this activity was due to their familiarity with and desire to use technology. Yet, as the students began to share their experiences with the DRL, they frequently spoke about various freedoms they were afforded via the DRL, namely freedom to choose the text they read and freedom to comment on the text using their "own" language. This theme was not anticipated, yet it was so overwhelmingly apparent throughout all of the interviews that it was decided to "lay aside" (Crotty, 1998, p. 78) our initial assumptions and proceed using a phenomenological data analysis process designed by van Kaam (1969). A phenomenological approach was chosen as its primary purpose is to shed light upon the phenomenon within the environment in which it exists. Specifically it was decided that van Kaam's data analysis model best suited the data as it esteems the implications of experiences felt, perceived and explained by individuals and investigates the explanations of those experiences (van Kaam, 1969). To that end, van Kaam defines his method as one that "seeks to disclose and elucidate the phenomena of behavior as they manifest themselves in the perceived immediacy" (p. 15).

Additionally, as the students were members of the first author's class, the study can be classified as a teacher research project. Teacher researchers are defined by Maclean and Mohr (1999) as subjective insiders that ask critical questions regarding the happenings and occurrences in their classroom, collect and analyze data to answer those questions, and make changes that lead to successful learning outcomes. However, there are limitations with conducting a teacher research study, primarily rooted in a "teacherly perspective" (Rudduck, 1985). While few would argue any qualitative research can, or perhaps should be completely objective, the unanticipated findings and new direction in term of analysis allowed the data to be looked at more objectively than initially assumed. That is, we looked at the data with no preconceived notions as we would have had we used our original assumptions as a lens to analyze the data.

\section{Interviews}

The phenomenon studied was the students' experiences with the DRL. To uncover the essence of this phenomenon, data collection centered on in-depth interviews with the 
participants. Each participant sat for an hour-long interview in a private office.

As per the consent form, the interviews were digitally recorded. The interview guide approach (Patton, 2001) was followed. The interview focused on students' perceptions of reading, past and present, as well as their experiences with the DRL. The participants also had access to their printed DRL during the interview. They were able to look through the logs as a way of refreshing their memories about what they and their partners had written and/or the articles they read.

Following van Kaam's (1969) model for data analysis, the following procedure was employed: (a) Classification of data into categories; (b) the reduction and linguistic transformation of the selections into specific terms; (c) the elimination of statements not inherent to the phenomenon; (d) the first hypothetical identification; (e) application of the hypothetical identification; (f) valid identification. Both researchers individually looked at the data set inductively, categorizing the data. The researchers then met and shared their categories. Any disparity was discussed and reevaluated. Elements that were not related to the phenomenon were eliminated, and categories which were in the participants' own language were transformed into specific terms. For example, excerpts from the raw data stated, "Cuz you could write whatever you felt like or you could like shorten it like you would do with text messages instead of writing it out" and "It was kinda like annotating but in a fun way because you can use the slang you wanted to use." Statements such as these were transformed by the researchers into "positive feelings when free to use their own language." These statements become hypothetical identifiers that were applied to the interview data by each researcher. The identifiers are hypothetical at this stage because it is "hardly possible to take into account at once all the details of all the descriptions" (van Kaam, 1969, p. 316) during any one phase of the analysis. Thus, the identifiers could, in fact, change as subsequent stages of analysis occur. Hypothetical identifiers were then applied to the data. Results of this last phase of analysis were again compared by the two researchers so as to validate the identifiers as those that most clearly identified portions of the data that spoke directly to the phenomenon being studied. Those sections of the interviews in which the researchers indicated the same identifier were lifted from the data sets and combined to illustrate the phenomenon experienced by the students while engaged in the DRL activity.

\section{Comments in the Digital Reading Logs}

Looking across the participants' DRLs, four common patterns emerged that spoke directly to the idea of engagement and comprehension while reading. First, strong opinions contradicting and supporting the content of the article could be seen in each participant's log. Many times exclamation points and capital letters were used indicating such emotion. Additionally, texting words, such as OMG (Oh My God), were inserted as a way to write out strong feelings the readers experienced while reading. Second, the students asked many questions of the text as well as of their partners. Many of the questions were clarifying questions when the students needed more information, not supplied in the text, to understand fully. The third pattern was that the majority of the comments made by the first reader were recognized by the second reader, mostly indicating agreement. Finally, the students tended to connect the text to their own lives (see Appendix). For the purpose of this paper, the findings directly reflect the students' interviews; however, the content of their logs strengthen their claims of increased engagements and comprehension. 


\section{Findings}

\section{Freedom-A Powerful Tool for Learning}

Based on the analysis of the data, it was found that allowing students to express themselves through the use of their own language can have a powerful impact on literacy growth. The importance of integrating students' own out-of-school language into school practices, particularly for marginalized populations, has been well documented (Gutierrez, BaquedanoLopez \& Alverez, 2000; Gutierrez, Baquendo-Lopez, Alverez \& Chiu, 1999). The findings of this study strengthen past research and focus on the unique type of language that students value. Additionally, findings show how implementing out-of-school language for academic tasks affords students the opportunity for greater success. For example, students reported that using their own language, which they described as "slang," "texting words," "computer words," and "normal talk," was directly connected to their increased understanding of the text used in the DRL activity. In other words, when students were allowed to speak freely, using their language of choice when discussing a text, they felt their engagement with, comprehension of, and motivation to read a text was bolstered compared to traditional "teacher" created homework.

Vicky explained this notion further:

Sue: .. . In your eyes, how was the Digital Reading Log different than your regular homework assignments?

Vicky: These are more interesting cuz you can pick what you wanna write about and talk about.

Sue: So you mean just the article or the comments?

Vicky: Both.

Sue: Ok, so you got to pick the article-

Vicky: And then you get to say what you wanna say.

Sue: So let me ask you this, you didn't say what you wanted to say on your homework assignments?

Vicky: Not really. I said what had to be said.

Sue: Ah ha. And what had to be said was because you were following directions?

Vicky: (nodding) For [the DRL] it was just like you could say whatever you want.

Sue: You like that?

Vicky: Yeah

Sue: Why?

Vicky: It was fun and it made me actually want to read a little bit.

Sue: Because you could say what you wanted to say?

Vicky: Yeah. I mean I didn't curse or anything but I said some funny stuff... Well it was to Tia and I'm friends with her so we both kinda talked like we would normally talk.

During Whitney's interview, she too expressed her enjoyment in being able to freely express herself during the DRL. When I asked her to describe the best aspect of the DRL she replied, "Um cuz I got to say whatever I wanted really. I just comment on what I thought about [the article]. It was kinda like annotating but in a fun way because you can use the slang you wanted to use."

Kevin succinctly explained the following when I asked him to describe his experience 
using comment boxes for the DRL:

Sue: In your eyes, how was using comment boxes for the Digital Reading Log different than [traditional homework]?

Kevin: Cuz you could write whatever you felt like or you could like shorten it like you would do with text messages instead of writing it out.

Sue: Did you like that?

Kevin: Yeah.

Sue: Why?

Kevin: It was fun.

Sue: So you say you could write whatever you wanted. And had you ever been able to do that before for an assignment for school?

Kevin: No. I can't remember anything that I could write whatever I felt like. You always had to write certain amounts about something. It was never about what you wanted to do. The topic was picked by the teacher you never got to pick.

Sue: Do you think you wrote differently because you knew I was not going to read it but rather another classmate?

Kevin: Yeah

Sue: Why do you think you changed in that way?

Kevin: I tried to write something funny or find [a] funny [article].

Sue: Did your language at all change when you were writing for your peers?

Kevin: Yeah I would say like, I guess you would say slang.

Later in the interview I asked the participants to discuss any ways in which the DRL helped or impacted their comprehension or understanding of the article. Kevin replied,

Kevin: I say [it helped me to] remember.

Sue: Why?

Kevin: Because you are writing [the comments] yourself so you can kinda remember [the comments] a little better. You could read them over real easily.

Sue: So because it's coming from you and it's in your own language. You would remember the articles better than if you hadn't used comment boxes?

Kevin: Yeah

In the above interviews, freedom of language and choice reigned. Students fully appreciated the idea of reading what they wanted to read and writing what they wanted to write. Vicky believed simply saying what she wanted to say increased her enjoyment of reading and consequently allowed her to read more than perhaps she normally would. Kevin, on the other hand, explained that transforming the author's words into his own language bolstered his ability to understand and remember what he read.

Second, was the notion that students enjoyed the freedom of using language that was familiar to them whether it was slang or texting language. Students felt comfortable interacting, particularly with peers, using language that they valued as a community of young adults. Paige explained this when she said, "Writing to another classmate is so fun; I guess cuz we're all young." The idea of communicating with each other, with language that would be considered 
counterscript (Gutierrez, 1993) to the official script of the classroom, made reading more enjoyable, less daunting, and seemingly more attainable than it had been with traditional teachergenerated homework.

Similar findings were noted in the study of Gutierrez et al. (1999) where Spanish speaking children were encouraged to participate in literacy activities, drawing on their "linguistic and sociocultural repertoires" rather than "traditional school criteria" (p. 89). While Gutierrez and her colleagues focused on two different languages, parallels can be drawn as the students viewed their out-of-school talk as a "language" much different than traditional in-school talk.

According to Gee (1996), the discourse of the classroom is shaped by the discourses of those who reside within. The hybrid nature of the classroom brings the students' out-of-school language into school as a way to promote and extend literacy growth within a Third Space. Researchers have found that students whose language practices do not resemble those practiced in classrooms will struggle to acquire new concepts (Gee et al., 1992). Additionally, Gee (1996) asserts that discourses are based in culture and ideologies which are formed through the practices of a particular group. Moje et al. (2008) state that students are engaging in a great deal of reading and writing acts outside of school, related to their affiliations with various popular cultural groups, but they are not reading and writing the types of texts that are valued by teachers. Thus, the need for teachers to invite students' out-of-school literacy practices into the classroom has never been more urgent.

Lastly, it should be noted that for several semesters prior to the focal semester, the students in the first author's developmental reading courses had been required to comment on texts (paper copies of articles supplied by the instructor) by recording their thoughts in the margins (in pencil). These texts were then turned in to the instructor for review. The thoughts recorded in this manner were few and not nearly as thought-provoking as those created in the DRL. Moreover, the paper and pencil task of recording thoughts was received with a great deal of resistance by the students and more often than not, this assignment was not completed. By shifting variables such as the texts and settings, "the question is no longer one of innate skill, but of the conditions under which the reader can and will employ his or her knowledge and skill..." (Lipson \& Wixson, 1986, p. 129).

\section{Summary and Further Thoughts}

As the purpose of this study was to investigate the phenomenon of students' heightened engagement with text and motivation during the DRL activity, the findings suggest that when the culture and ideologies of young adult students are valued in the classroom, the context of the reading situation shifts from a school context to a more blended home-school context. In essence, this is a Third Space, which Gutierrez (2008) argues is like a Zone of Proximal Development, allowing the optimum opportunity for growth. Students' freedom of language use, as well as the freedom to choose their own texts, propelled their ability to engage with and comprehend a text inside the classroom because aspects of their culture, i.e., students' everyday language and the kinds of texts typically read outside of school, were being valued. The findings of this study support Pane's (2009) assertion that a Third Space within the classroom can be thought of as "a navigational tool for guiding students across the boundaries" of texts whose language may be considered privileged "through their everyday funds of knowledge and discourse" (p. 67). 
Studying the phenomenon of the students' experiences with the DRL is important to those educators who work with struggling adolescent or adult readers who are disengaged with in-school reading tasks and consequently do not comprehend what they read. In their 2008 US Department of Education report on improving adolescent literacy, Kamil, Borman, Dole, Kral, Salinger, and Torgesen (2008) suggested that teachers "make literacy experiences more relevant to students' interests, everyday life, or important current events" (p. 26), as well as create "opportunities to bridge the activities outside and inside the classroom" (p. 28). The DRL meets this challenge.

Collectively, the participants felt that if they could utilize the DRL activity for reading assignments in their other courses, they would, indeed, be more successful. Unfortunately, many of their texts were not available online, and thus the comment box function was not able to be utilized. Still, many students confirmed that they transferred the strategies enhanced by the DRL, such as commenting on important points or asking questions of the text, to complete their readings in other courses. Some of the participants went a step further and taught those strategies to friends who were struggling with reading assignments in their own courses. In the end, it appears that Tapscott's (1999) bold proclamation to give "students the tools and they will be the single most important source of guidance on how to make their schools relevant and effective places to learn" (p. 11) may be precisely correct. The idea of tools should not be limited, however, to technology alone as Tapscott suggests, but language, popular cultural practices, and beliefs as well. As found in this study, the unseen tools embedded within popular cultural practices can have a profound impact on literacy growth.

\section{Methodological Limitations and Future Directions for Research}

Methodologically speaking, including more students in the study would strengthen the findings. Additionally, there is no question there was some bias in the interpretation of the data in that the first author was also the instructor, and inevitably wanted her students to succeed. Lastly, the length of the study was a limitation in that the participants could not be followed into subsequent college courses to witness if the impact of the DRL carried into other classes.

The conclusions drawn from the findings indicate that more research needs to be focused on the integration of technology as a means of creating a successful Third Space where students can thrive. Older struggling readers, such as the students in this study often are subject to drilllike remediation programs (Maxwell, 1997; Wood, 1997) because there has been so little research on this population (Grubb, 2001; Paulson, Laine, Biggs, \& Bullock, 2003). Could simply shifting the context of literacy instruction for older students be a key factor in these students finding success with reading comprehension? Does out-of-school culture and ideology have such an influence over students' success that by merely allowing these ideologies into the classroom a struggling, unmotivated reader can turn around? Lastly, while the participants did not attribute their increased engagement and comprehension directly to the use of technology, is there more of a connection between digital texts and motivation than the data revealed? Larger, more in-depth studies examining these questions would certainly aid older students, who more often than not, will continue to struggle with reading, making goal attainment challenging, if not impossible. 
References

Alvermann, D. E., \& Hagood, M. C. (2000). Critical media literacy: Research, theory, and practice in "new times." Journal of Educational Research, 93, 193-205.

Boylan, H. (2009). Targeted intervention for developmental education students (T.I.D.E.S.). Journal of Developmental Education, 32(3), 14-23.

Crotty, M. (1998). The foundations of social research: meaning and perspective in the research process. London, UK: SAGE Publications Ltd.

Delpit, L. (2006). Lessons from teachers. Journal of Teacher Education, 57(3), 220-231.

Eccles, J. S., \& Midgley, C. (1989). Stage-environment fit: Developmentally appropriate classrooms for young adolescents. In C. Ames \& R. Ames (Eds.), Research on motivation in education: Goals and cognitions (pp. 139-186). San Diego, CA: Academic Press.

Gambrell, L. B. (1996). Creating classroom cultures that foster reading motivation. The Reading Teacher, 50(1), 14-25.

Gee, J. (1996). On mobots and classrooms: The converging languages of the new capitalism and schooling. Organization, 3(3), 385-407.

Gee, J. (2000). Discourse and sociocultural studies of reading. In M. L. Kamil, P. B. Mosenthal, P. D. Pearson, \& R. Barr (Eds.), Handbook of reading research (Vol. III, pp. 195-207). Mahwah, NJ: Erlbaum.

Gee, J, (2001). Reading as situated language: A sociocognitive perspective. Journal of Adolescent and Adult Literacy. 44(8), 714-725.

Gee, J. P., Michales, S., \& O’Connor, C. (1992). Discourse analysis. In M. D. LeCompte, W. Millroy, \& J. Preissle, (Eds.), Handbook of qualitative research in education. (pp. 227291). New York, NY: Academic Press.

Grubb, N. W. (2001). From black box to Pandora's box: Evaluating remedial/developmental education. New York, NY: Teachers College, Columbia University, Community College Research Center.

Guthrie, J. T., \& Davis, M. H. (2003). Motivating struggling readers in middle school through an engagement model of classroom practice. Reading and Writing Quarterly, 19, 59-85.

Guthrie, J. T., Hoa, L. W., Wigfield, A., Tonks, S. M., Humenick, N. M., \& Littles, E. (2007). Reading motivation and reading comprehension growth in the later elementary years. Contemporary Educational Psychology, 32(3), 282-313.

Guthrie, J. \& Wigfield, A. (2000). Engagement and motivation in reading. In M. Kamil, P. Mosenthal, P. D. Pearson, \& R. Barr (Eds.), Handbook of reading research (Vol. III, pp. 403-422). Mahwah, NJ: Lawrence Erlbaum.

Gutiérrez, K. (1993). How talk, context, and script shape contexts for learning to write: A cross case comparison of journal sharing. Linguistics and Education, 5 (3 \& 4), 335-365.

Gutierrez, K. (2008). Developing a sociocritical literacy in the third space. Reading Research Quarterly, 43(2), 148-164.

Gutiérrez, K., Baquedano-Lopez, P., \& Alvarez, H. (2000). The crisis in Latino education: Challenging the current debate. In C. Tejeda, C. Martinez, \& Z. Leonardo (Eds.), Demarcating the Borders of Chicana(o)/Latina(o) education (pp. 213-232). Cresskill, NJ: Hampton Press Inc.

Gutiérrez, K. D., Baquedano-López, P., Alvarez, H. H., \& Chiu, M. M. (1999). Building a 
culture of collaboration through hybrid language practices. Theory into Practice, 38(2), 87-92.

Gutiérrez, K., Baquedano-Lopez, P., \& Turner, M.G. (1997). Putting language back into language arts: When the radical middle meets the third space. Language Arts, 74(5), 368378.

Gutiérrez, K., Rymes, B., \& Larson, J. (1995). Script, counterscript, and underlife in the Classroom: James Brown versus Brown v. Board of Education. Harvard Educational Review, 65(3), 445-471.

Heron-Hruby, A., Hagood, M. C., \& Alvermann, D. E., (2008). Switching places and looking to adolescents for the practices that shape school literacies, Reading \& Writing Quarterly: Overcoming Learning Difficulties, 24(3), 311-334.

Kamil, M. L., Borman, G. D., Dole, J., Kral, C. C., Salinger, T., \& Torgesen, J. (2008). Improving adolescent literacy: Effective classroom and intervention practices: A practice guide (NCEE \#2008-4027). Washington, DC: National Center for Education Evaluation and Regional Assistance, Institute of Education Sciences, U.S. Department of Education. Retrieved from http://ies.ed.gov/ncee/wwc/PracticeGuide.aspx?sid=8

Labbo, L. (2006). Literacy pedagogy and computer technologies: Toward solving the puzzle of current and future classroom practices. Australian Journal of Language and Literacy, 29(3), 199-209.

LeLoup, J. W., \& Ponterio, R. (2003). Second language acquisition and technology: A review of the research, CAL Digest, Center for Applied Linguistics. Retrieved from http://www.cal.org/resources/digest/0311leloup.html

Leu, D. J., Kinzer, C. K., Coiro, J. L., \& Cammack, D. W. (2004). Toward a theory of new literacies emerging from the Internet and other information and communication technologies. In R. B. Ruddell \& N. J. Unrau (Eds.), Theoretical models and processes of reading (pp. 1570-1611). Newark, DE: International Reading Association.

Lipson, M. Y., \& Wixson, K. K. (1986). Reading disability research: An interactionist perspective. Review of Educational Research, 56(1), 111-136.

MacLean, M. S., \& Mohr, M. M. (1999). Teacher-researchers at work. Berkeley, CA: The National Writing Project.

Maxwell, M. (1997). The dismal state of required developmental reading programs: Roots, causes and solutions. Kensington, MD: MM Associates.

Medina, J. (2010, April 16). Deal reached to fix teacher discipline process. New York Times. Retrieved from http://query.nytimes.com/gst/fullpage.html?res=9405EEDC1531F935A25757C0A9669D $8 \mathrm{~B} 63 \& \mathrm{scp}=3 \& \mathrm{sq}=\& \mathrm{st}=\mathrm{nyt}$

Meskill, C., \& Mossop, J. (2000) Technologies use with learners of English as a second language. Journal of Educational Computing Research, 22(3), 265-284.

Moje, E., Ciechanowski, K., Kramer, K., Ellis, L., Carrillo, R., \& Collazo, T. (2004). Working toward third space in content area literacy: An examination of everyday funds of knowledge and discourse. Reading Research Quarterly, 39(1), 38-70.

Moje, E. B., Overby, M., Tysvaer, N., \& Morris, K. (2008). The complex world of adolescent literacy: Myths, motivations, and mysteries. Harvard Educational Review, 78(1), 107154.

Moll, L.C., Armanti, C., Neff, D., \& Gonzalez, N. (1992). Funds of knowledge for teaching: 
Using a qualitative approach to connect homes and classrooms. Theory into Practice, 31 (2), 132-141.

Moore, D. W., Bean, T. W., Birdyshaw, D., \& Rycik, J. A. (1999). Adolescent literacy: A position statement. Journal of Adolescent \& Adult Literacy, 43(1), 97-112.

Pane, D. M., (2009). Third space: Blended teaching and learning. Journal of the Research Center for Educational Technology, 67(5), 64-92.

Patton, M. Q. (2001). Qualitative evaluation and research methods (3rd ed.). Thousand Oaks, CA: Sage Publications, Inc.

Paulson, E., Laine, E., Biggs, S., \& Bullock, T. (Eds.) (2003). College reading research and practice. Newark, DE: International Reading Association.

Polkinghorne, D. E. (1989). Phenomenological research methods. In R. S. Valle \& S. Halling (Eds.), Existential-phenomenological perspectives in psychology: Exploring the breadth of human experience (pp. 41-60). New York, NY: Plenum Press.

Reynolds, P. L., \& Symons, S. (2001). Motivational variables and children's text search. Journal of Educational Psychology, 93(1), 14-23.

Rudduck, J. (1985). Teacher research and research-based teacher education. Journal of Education for Teaching, 11(3), 281-289.

Schiefele, U. (1999). Interest and learning from text. Scientific Studies of Reading, 3, 257-280.

Tapscott, D. (1999). Educating the net generation. Educational Leadership, 56(5), 6-11.

The 21st Century Workforce Commission. (2000). A nation of opportunity: Building America's 21st century workforce. Washington, DC: U.S. Department of Labor.

van Kaam, A. L. (1969). Existential foundations of psychology. New York, NY: Image Books.

Vygotsky, L. S. (1978). Mind in society: The development of higher psychological processes. Cambridge, MA: Harvard University Press.

Warschauer, M. (2006). Laptops and literacy: Learning in the wireless classroom. New York, NY: Teachers College Press.

Wood, N. V. (1997). College reading instruction as reflected by current reading textbooks. Journal of College Reading and Learning, 27(3), 79-95.

\section{Author Biographies}

Sue Nash-Ditzel is an elementary principal in Connecticut. Her research agenda focuses on understanding why some readers struggle and alternative strategies that promote positive shifts in reading perceptions and behaviors.

Tammy Brown is an assistant professor of literacy education at Marywood University. Her recent research involves understanding the disconnect between out-of-school and in-school literacies as well as ways educators can bridge the gap between home and school to promote successful reading practices.

\section{Endnotes}

i "Discourse integrates ways of listening, writing, reading, acting, interacting, believing, valuing and feeling (and using various objects, symbols, images tools, and technologies) in the service of enacting meaningful socially situated identities and activities" (Gee, 2001, p. 719). 


\section{Appendix}

Deal Reached to Fix Teacher Discipline Process

By JENNIFER MEDINA

Published: April 16, 2010

Mayor Michael R. Bloomberg and the city's teachers union have agreed to do away with "rubber rooms" and speed up hearings for teachers accused of wrongdoing or incompetence, ending a disciplinary system that has made both City Hall and the teachers' union subjects of ridicule.

Under the agreement, teachers the city is trying to fire will no longer be sent to the rubber rooms, known as reassignment centers, where the teachers show up every school day, sometimes for years, doing no work and drawing full salaries. Instead, these teachers will be assigned to administrative work or duties outside classrooms in their schools while their cases are pending.

The centers have been a source of embarrassment for both the Bloomberg administration and the United Federation of Teachers, as articles in newspapers and magazines detailed teachers running businesses out of the rubber rooms or dozing off for hours on end.

Officials said the agreement would also shorten the time it takes for cases to be resolved by allowing more arbitrators to be hired and requiring them to hear cases more frequently. Cases that lasted several years could now be completed in months. 